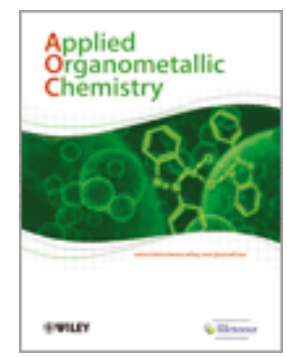

\title{
The Synthesis and Properties of Nanoscale Ionic Materials
}

\begin{tabular}{|r|l|}
\hline Journal: & Applied Organometallic Chemistry \\
\hline Manuscript ID: & AOC-09-0110.R3 \\
\hline Wiley - Manuscript type: & Research Article \\
\hline Date Submitted by the & 02-Jan-2010 \\
\hline Complete List of Authors: & $\begin{array}{l}\text { Rodriguez, Robert; Cornell University, Materials Science and } \\
\text { Engineering } \\
\text { Herrera, Rafael; Cornell University, Chemical and Biomolecular } \\
\text { Engineering } \\
\text { Bourlinos, Athanasios; Cornell University, Materials Science and } \\
\text { Engineering } \\
\text { Li, Ruipeng; King Abdullah University of Science and Technology, } \\
\text { Department of Materials Science and Engineering } \\
\text { Amassian, Aram; King Abdullah University of Science and } \\
\text { Technology, Department of Materials Science and Engineering } \\
\text { Archer, Lynden; Cornell University, Chemical and Biomolecular } \\
\text { Engineering } \\
\text { Giannelis, Emmanuel; Cornell University, Materials Science and } \\
\text { Engineering }\end{array}$ \\
\hline Keywords: & \begin{tabular}{l} 
Nanostructures, nanoparticles, ionic liquids, colloidal suspensions \\
\hline \hline
\end{tabular} \\
\hline \hline
\end{tabular}

\section{s ScholarONE" \\ Manuscript Central}




\title{
The Synthesis and Properties of Nanoscale Ionic Materials
}

${ }^{1}$ Robert Rodriguez, ${ }^{2}$ Rafael Herrera, ${ }^{1}$ Athanasios B. Bourlinos, ${ }^{3}$ Ruipeng Li, ${ }^{3}$ Aram Amassian, ${ }^{2}$ Lynden A. Archer, ${ }^{1}$ Emmanuel P. Giannelis

${ }^{1}$ Department of Materials Science and Engineering, Cornell University, Ithaca, NY 14853, USA

${ }^{2}$ Department of Chemical and Biomolecular Engineering, Cornell University, Ithaca, NY 14853, USA

${ }^{3}$ Department of Materials Science and Engineering, King Abdullah University of Science and Technology, Jeddah, Kingdom of Saudi Arabia

Acknowledgements: We gratefully acknowledge the support of Award No. KUS-C1-018-02 made by King Abdullah University of Science and Technology (KAUST). We also acknowledge use of facilities at the Cornell Center for Materials Research. RR acknowledges the support of an IGERT Fellowship (NSF DGE-0654193).

\begin{abstract}
In this article we discuss the effect of constituents on structure, flow, and thermal properties of Nanoscale Ionic Materials (NIMs). NIMs are a new class of nanohybrids consisting of a nanometer sized core, a charged corona covalently attached to the core, and an oppositely charged canopy. The hybrid nature of NIMs allows for their properties to be engineered by selectively varying their components. The unique properties associated with these systems can help overcome some of the issues facing the implementation of nanohybrids to various commercial applications, including carbon dioxide capture, water desalinization, and as lubricants.
\end{abstract}

\section{Introduction}

The development of several techniques to synthesize nanoparticles of various shapes, sizes, compositions, and mass distributions (e.g. hollow vs. rigid) has led to an increasing 
number of published research articles over the last several years. A search in the Web of Science shows that in 2007 there were over 14000 papers published on nanoparticles ${ }^{[1]}$, and by 2008 that number had increased to over 19 000, indicating a rapidly growing interest in this field. A more careful analysis of these publications indicates that the interest is broad-based, with major efforts in academia, industry, and government laboratories. The growing interest in nanoparticle systems is readily rationalized in terms of the unusual opportunities these systems present for tuning matter on small scales, as well as in terms of the large numbers of consumer products such as paints, inks, coatings, that may be impacted by these materials.

The ability to combine nanoscale particles with organic polymers provides additional synergies between the ease of processing provided by the organic polymer, and function imparted by the nanoparticle. The resultant nanohybrid systems have attracted broad-based scientific and applications interest worldwide. Polymer nanocomposites are arguably the simplest, and certainly the best known example of a nanohybrid materials system ${ }^{[2-12]}$. Formed by physical mixing of one or more organic polymer hosts with inorganic nanoparticles, these systems have attracted growing interest for the last two decades ${ }^{[3,5-7,9-11,13]}$. Despite this interest, challenges with poor dispersion and lack of control of interfacial strength between the nanometer sized particles and the matrix polymer have prevented polymer nanocomposites ${ }^{[14]}$ from realizing their full potential.

We discuss here a new materials platform that addresses the challenges associated with existing nanohybrids. Termed nanoscale ionic materials (NIMs), these materials are organicinorganic hybrids typically composed of a nanometer sized inorganic core, surface functionalized with a charged corona. An oppositely charged canopy consisting of a low molecular weight 
polymer is introduced to balance the charge ${ }^{[15,16]}$. Because of the hybrid character of NIMs, their physical properties can be tailored by varying the size, shape and composition of the core, corona, and canopy as well as external parameters such as temperature, mechanical deformation, electric and magnetic fields. For example, our previous work has shown that by varying the molecular weight and grafting density of the canopy we can synthesize materials which can range in flow properties from liquid-like to waxy solids ${ }^{[17,18]}$. The canopy, which serves as the effective fluidization medium in NIMs, is tethered to the cores by ionic bonds leading to a low vapor pressure and yielding low VOC fluids with an unusual combination of properties. From these examples of NIMs properties, it is apparent that they do share some of the characteristics associated with ionic liquids such as an ionic attraction between the components in NIMs, but the molecular architectures of NIMs and ionic liquids are completely different ${ }^{[19-23]}$. Although measurements do not yet exist for the electrostatic interaction energy between the corona and canopy, we assume that the energy values may be on the same order of magnitude as those calculated for ionic liquids which have a Coulomb energy that ranges from $75-200 \mathrm{~kJ} / \mathrm{mol}^{[24,25]}$. Future studies involving Surface Forces Apparatus measurements will hopefully yield more information on the interaction energies associated with the corona and canopy. In this article we present a model NIMs system based on $18 \mathrm{~nm}$ diameter silica cores, a sulfonic acid silane as the corona, and a tertiary amine as the canopy. Results on how the constituents affect the thermal, structural, and dynamic properties of NIMs will be presented.

\section{Nanoscale Ionic Materials}

Below we briefly discuss previously published work on NIMs to show the generality of the method. The synthesis of the first generation of NIMS involves covalently grafting a cationic 
amine such as $\left(\mathrm{CH}_{3} \mathrm{O}\right)_{3} \mathrm{Si}\left(\mathrm{CH}_{2}\right)_{3} \mathrm{~N}^{+}\left(\mathrm{CH}_{3}\right)\left(\mathrm{C}_{10} \mathrm{H}_{21}\right)_{2} \mathrm{Cl}^{-}$to the surface of the nanoparticle core, resulting in a positively charged corona around the core particle $e^{[15,17,26,27]}$. To maintain charge neutrality, a counter-ion must always be present. If the counter anion is $\mathrm{Cl}^{-}$, solid powders are obtained with no phase transitions observed even when the material is heated to temperatures above the decomposition temperature of the corona. Exchanging the $\mathrm{Cl}^{-}$ions with a larger organic counter-ion such as $\mathrm{R}\left(\mathrm{OCH}_{2} \mathrm{CH}_{2}\right)_{7} \mathrm{O}\left(\mathrm{CH}_{2}\right)_{3} \mathrm{SO}_{3}^{-}(\mathrm{R}=$ alkyl chain $)$ or any other appropriate anionic oligomer results in liquid-like materials which can flow at room temperature. Previous work has shown that materials with organic contents greater than $75 \mathrm{wt} \%$ are required to achieve fluidity ${ }^{[16,17,26]}$. Since the relative ratios of inorganic to organic content are strongly dependent on the molecular weight and composition of the canopy material, the degree of over exchange (addition of excess un-reacted canopy) required to produce systems resembling liquids will increase as the size of the counter-ion decreases.

The synthesis of second generation NIMs involves a complementary approach where the sign of the charges on the corona and canopy is opposite to that of first generation systems. Core particles are surface modified by covalently grafting 3-(trihydroxysilyl)-1-propane sulfonic acid (SIT), resulting in a net negative charge on the surface ${ }^{[16]}$. A proton is present to maintain the charge neutrality of the system. As was observed in the first generation NIMs, these particles appear as powders and show no visible fluid behavior in the absence of a solvent. These acidic particles are then reacted with a PEG-substituted amine in a simple acid-base reaction. During the reaction, the acidic groups on the cores protonate the amine on the canopy leading to opposite charges on the corona and canopy and an electrostatic interaction between the two, which has the effect of stabilizing the particles. 
Beside silica, several other NIMs have been reported with fascinating physical properties. For example, when iron oxide is used as core material, magnetically responsive NIMs are obtained $^{[15]}$. The iron oxide core maintains its super paramagnetic nature and yields the first example of a solvent-free ferrofluid. This approach has also been applied to a class of protonic solid conductors called polyoxometalates $(\mathrm{POMs})^{[28]}$. POMs consist of nanometer sized clusters of early transition metal ions octahedrally coordinated to oxygen ${ }^{[29]}$; they have been considered as potential candidates for electrolytes in fuel cell applications ${ }^{[30-35]}$. A major drawback of POMs is that their conductivity is highly dependent on humidity and temperature, limiting the applicability of these materials ${ }^{[30,32]}$. To overcome these challenges, NIMs based on POMs as their cores were obtained by a partial exchange of the surface protons in the core cluster by PEGcontaining quaternary ammonium cation ${ }^{[28]}$. This reaction formed fluid proton conductors with conductivities about 3-4 orders of magnitude higher than their solid-state analogs. Additionally, by applying the Walden rule, $\Lambda \eta=$ constant, where $\Lambda$ is the equivalent conductivity and $\eta$ is the viscosity of the liquid $^{[22,36]}$, we found that POM-based NIMs behave like super-ionic liquids with more efficient conduction mechanisms such as superionic slip of ions or the Grothhus mechanism.

NIMs based on other oxide cores, including $\mathrm{TiO}_{2}{ }^{[17]}, \mathrm{ZnO}^{[27]}$ nanoparticles and even layered organosilicate nanoparticles ${ }^{[37]}$, have been reported. An interesting feature manifested by NIMs based on $\mathrm{ZnO}$ is their high quantum yield photoluminescence, a property that holds promise for nanoscale hybrid materials in optics and photonics. It may even be possible to dope with different chemical species to tune the emission towards the UV, opening up the possibility for lasing in $\mathrm{ZnO}$ nanoparticles. In the case of layered organic-inorganic nanoparticles, NIMs were synthesized in-situ by a controlled hydrolytic polymerization and assembly of 
octadecltrichlorosilane to form a solid at room temperature, which undergoes a reversible solidto-liquid transition.

The first case of a solvent-free plasmonic fluid was reported by synthesizing NIMs with metal cores, such as gold nanorods $(\mathrm{GNRs})^{[38]}$. The localized surface plasmon resonance (LSPR) of metal nanoparticles is highly sensitive to the local environment of nanoparticles and to interparticle interactions, such as in the presence of GNR clusters. Interesting features manifested by plasmonic fluids containing GNR clusters include the reversible color changes and plasmonic responses of the fluid in response to external stimuli such as mechanical shearing. The reversible changes are due to variations in the position and intensity of plasmon peaks as GNRs in the fluid are temporarily aligned with the direction of shearing and the LSPR is perturbed.

Our previous work has also shown that NIMs are not limited to inorganic cores, but organic cores can be used as well. Meltable, amphiphilic NIMs based on carbon nanotubes are synthesized using a two step process where first, the nanotubes are acid oxidized to create polar hydrophilic groups (-COOH). Next, a poly(ethylene glycol)- substituted tertiary amine reacts with the carboxylic groups in an acid-base reaction ${ }^{[18]}$. The resulting material is solid at room temperature but undergoes a solid-liquid transition at $35^{\circ} \mathrm{C}$ and is dispersible in both organic and aqueous solvents. It appears that NIMs can be synthesized out of any nanostructured or molecular core including DNA. Fluid DNA can be synthesized in the absence of any solvents by replacing the sodium counter-ions of DNA with a quaternary ammonium ${ }^{[17]}$. A recent report by Perriman et. al. shows the first example of a solvent-free liquid protein based on a ferritinpolymer construct $^{[39]}$. In this work, cationic ferritin was electrostatically bound with a stoichiometric amount of anionic polymer surfactant to produce a single component liquid 
protein nanostructure. These examples show that NIMs are not limited to inorganic cores, but can be synthesized using various organic, biological and hybrid compositions. The versatility of the chemistry therefore allows the synthesis of materials with a variety of compositions and properties, opening several new avenues or research and potential applications.

\section{Experimental Section}

\section{Nanoparticle Surface Modification}

Second generation NIMs were prepared following a previously reported method ${ }^{[16]}$. Scheme $1 \mathrm{a}$ shows an outline of the procedure followed to graft the anionic corona to the surface of the nanoparticles. In a flask, 3g of Ludox HS 30 colloidal silica (Sigma Aldrich, mean diameter $18 \mathrm{~nm}$ ) was diluted with $22 \mathrm{ml}$ of $18 \mathrm{M} \Omega$-cm deionized water. In a separate flask $4 \mathrm{~g}$ of 3 (trihydroxysilyl)-1-propane sulfonic acid (SIT, 40 wt. \%, Gelest) was diluted with 20ml of $18 \mathrm{M} \Omega-\mathrm{cm}$ deionized water. The colloidal silica suspension was slowly added to the SIT suspension while stirring vigorously. A solution of 1M sodium hydroxide solution (Sigma Aldrich, $\mathrm{NaOH}$ ) was added drop wise to the silica-SIT solution until a $\mathrm{pH}$ of about 5 was reached. The entire solution was then sealed and heated to $70^{\circ} \mathrm{C}$ while vigorously stirring for 24h. After that, the suspension was cooled to room temperature and placed into dialysis tubing (Spectra/Por RC Biotech Membrane, 15K MWCO, $16 \mathrm{~mm}$ flat width) and dialyzed against $18 \mathrm{M} \Omega-\mathrm{cm}$ deionized water for three days while changing the water twice a day. After dialysis, the functionalized silica suspension was run through an ion exchange column (Sigma Aldrich, Dowex HCR-W2 ion exchange resin) to remove $\mathrm{Na}^{+}$ions and protonate the sulfonic acid groups residing on the silica nanoparticle surface. 


\section{NIMs Synthesis}

NIMs were prepared by dissolving a desired amount of tertiary amine (Akzo Nobel, Ethomeen ${ }^{\circledR}$ $\mathrm{C} / 25,\left(\left(\mathrm{C}_{18} \mathrm{H}_{37}\right) \mathrm{N}\left[\left(\mathrm{CH}_{2} \mathrm{CH}_{2} \mathrm{O}\right)_{\mathrm{m}} \mathrm{H}\right]\left[\left(\mathrm{CH}_{2} \mathrm{CH}_{2} \mathrm{O}\right)_{\mathrm{n}} \mathrm{H}\right], m+n=25, \mathrm{MW}=850 \mathrm{~g} / \mathrm{mol}\right)$ in $18 \mathrm{M} \Omega-\mathrm{cm}$ deionized water to a concentration of $5 \mathrm{wt} \%$ (Scheme 1c). The amine solution was then added drop wise to react with the silica solution while closely monitoring the $\mathrm{pH}$ as shown in Error! Reference source not found.Scheme 1b. Upon reacting the corona and the canopy, all remaining water is slowly removed under vacuum at a temperature of $35^{\circ} \mathrm{C}$ to yield a clear, amber-colored material. Figure 1 shows a schematic of what NIMs consist of in the final state, a nanoparticle core with a charged corona and associated counter-ions. The TEM image in Figure 1 also shows that the nanoparticles do not aggregate and remain as single units once all the solvent has been removed.

\section{Instrumentation}

TGA measurements were obtained on a TA Instruments model Q500 under $\mathrm{N}_{2}$ flow in the temperature range of $25^{\circ} \mathrm{C}$ to $550^{\circ} \mathrm{C}$ at a heating rate of $10^{\circ} \mathrm{C} / \mathrm{min}$. Bright field TEM images were obtained at $120 \mathrm{kV}$ with a FEI Tecnai T12 Spirit Twin TEM/STEM. The TEM images were taken by dissolving NIMs in acetone, placing a $5 \mu \mathrm{L}$ drop of the dispersion on a copper grid and evaporating the solvent. Rheological measurements were obtained on an ARES Rheometer and Paar Physica Modular Compact Rheometer 501 (MCR-501). A cone and plate measurement system was employed with a $25 \mathrm{~mm}$ diameter and $1^{\circ}$ cone angle with all measurements taken at $30^{\circ} \mathrm{C}$. Flow curves for all samples were obtained using a combination of steady shear tests on the ARES and creep experiments on the MCR-501. Small-angle x-ray scattering measurements were taken at the Cornell High Energy Synchrotron Source (CHESS, D-Line) by loading the 
samples into a tube with a diameter of $0.2 \mathrm{~mm}$. Exposure times varied between $0.5-1 \mathrm{~s}$, depending on the degree of scattering. Differential Scanning Calorimetry (DSC) experiments were performed with a TA Instruments Q1000, equipped with a liquid nitrogen cooling system. The samples were first heated from room temperature to $100^{\circ} \mathrm{C}$ at a rate of $10^{\circ} \mathrm{C} / \mathrm{min}$, annealed for 5 min and then cooled to $-140^{\circ} \mathrm{C}$ at the same rate. Data from the second heating cycle is reported using a heating rate of $10^{\circ} \mathrm{C} / \mathrm{min}$. DSC measurements were performed using airtight cramped aluminum pans. Dielectric spectroscopy (DS) was performed using a Novocontrol Beta Broadband Dielectric System (BDS) equipped with a Quatro Cryosystem temperature controller. The sample cell consisted of two brass electrodes $20 \mathrm{~mm}$ in diameter and a $0.25 \mathrm{~mm}$ thick Teflon spacer with a cross sectional area of $87.1 \mathrm{~mm}^{2}$. The samples were loaded inside the Teflon ring and sandwiched in between the brass electrodes. The dielectric measurements were performed under a temperature controlled $\mathrm{N}_{2}$ environment in a range of -50 to $120^{\circ} \mathrm{C}$. The amplitude of applied AC voltage was $1 \mathrm{~V}$ in a frequency range of 1 to $3 \times 10^{6} \mathrm{~Hz}$. All samples were dried under vacuum for 24 hours before characterization. The complex dielectric function $(\varepsilon)$ is defined by $\varepsilon$ $=\varepsilon^{\prime}-i \varepsilon^{\prime \prime}$ where $i=\sqrt{ }-1, \varepsilon^{\prime}$ and $\varepsilon^{\prime \prime}$ are the real (dielectric permittivity) and imaginary part (dielectric loss), respectively. Both $\varepsilon^{\prime}$ and $\varepsilon^{\prime \prime}$ are functions of frequency ( $\omega=2 \pi f$, where $f$ is in Hertz) and temperature $(T)$ at a given pressure ${ }^{[40-42]}$.

\section{Results and Discussion}

\section{NIMs Synthesis}

The requirements for creating NIMs are fairly straightforward: First, a nanoparticle with desired chemistry, size and shape must be synthesized. Methods for carrying out this synthesis 
are available in several notable reviews ${ }^{[14,43-47]}$. Second, the surface of the nanoparticle is densely functionalized with a charged molecular species termed the corona. Finally, the counterion (termed the canopy) maintaining charge neutrality of the corona is exchanged using an oligomer (short polymer) with the same charge. Considering the range of nanoparticle chemistries, sizes, shapes, and mass distributions available and the vast library of organic polymers (chemistry, molecular weight, architecture) available for forming the corona and canopy, it is clear that this article must focus on representative systems. For this article we chose a simple model NIMs system based on $18 \mathrm{~nm}$ diameter silica nanoparticles as the core, a corona of propyl-sulfonic acid silane, and a tertiary poly(ethylene glycol)-substituted amine as the canopy (Scheme 1). This particular model system was selected because of the ease with which the core volume fraction and the composition of the canopy can be tuned to prepare a broad range of NIMs compositions and properties.

Using a titration curve as shown in Figure 2, the equivalence point of the reaction between the acidic corona and basic canopy can be used to find the 1:1 stoichiometric ratio of corona to amine which occurs at the point where the slope change is greatest. For the $18 \mathrm{~nm}$ diameter silica particles used in this study, the equivalence point for materials synthesized with the tertiary amine occurs at a core volume fraction of $\varphi=0.308$. The equivalence point for NIMs can be tuned by varying the grafting density of the corona molecules and molecular weight of the canopy. The number of corona molecules can be varied by using different types and sizes of cores, doing so will result in different numbers of attached corona groups and will require different quantities of amine to fully neutralize the acidic groups. Alternatively, by changing the molecular weight of the canopy one can also shift the location of the NIMs transition. For example, an amine with a larger molecular weight will be more massive and will occupy a 
greater volume, thereby shifting the NIMs transition to lower $\varphi$. Once the equivalence point of the reaction is located, NIMs systems can be synthesized with a sub-equivalence or overequivalence of nanoparticles.

\section{Structure and Rheology of NIMs}

Since early reports of colloids and polymer nanocomposites, it has been shown that the concentration and type of fillers has a significant effect on the physical properties of such systems $^{[4,48-59]}$. For instance, the chemistry of paints and shampoos is carefully controlled to yield desired viscosities and behaviors such as shear thinning and thickening. Similarly, further development of NIMs for emerging applications requires that we understand the influence of the nanoparticle fillers on the nanoscale structure of NIMs and on their physical properties, including viscosity, degree of shear thinning and thickening. Such insight may be gained by combining mechanical rheometry with x-ray scattering studies of NIMs.

Flow curves for NIMs based the tertiary amine are shown in Figure 3. As is observed in many different types of systems including colloids ${ }^{[48,54,60]}$ and polymer nanocomposites ${ }^{[58,61,62]}$, the viscosity of NIMs strongly depends on the core volume fraction. The range of samples which show Newtonian behavior appears to strongly depend on core volume fraction. For example, Figure 3 shows that tertiary amine-based NIMs display Newtonian behavior up to core volume fractions of $\varphi \sim 0.19$, above this concentration non-Newtonian effects such as shear thinning begin to manifest. From past observations and results presented in this work it seems that all NIMs appear to show the entire range of behavior from Newtonian liquid to NonNewtonian with strong shear thinning at higher core volume fractions. The flow behavior can be controlled by varying not only the core volume fraction, but also on the amine architecture and 
molecular weight ${ }^{[16,26]}$. These results then lead to the theory that NIMs with a variety of flow behavior can be synthesized by carefully controlling the core size, volume fraction, and canopy composition.

The viscosity dependence on core volume fraction can be further quantified in a plot of the reduced viscosity (ratio of zero-shear viscosity of NIMs to viscosity of pure canopy) which is shown in Figure 4. The reduced viscosity of tertiary amine-based NIMs diverges at $\varphi=0.25$, a value much lower than the expected $\varphi_{\max }=0.64$ observed for suspensions of hard spheres ${ }^{[48,54 \text {, }}$ 63]. This can be explained by assuming that the effective volume fraction of the cores must include contributions from not only the corona, but the canopy as well. During an applied deformation, it is the entire system (core, corona and canopy) which flows together and contributes to the core volume. The cores are then effectively larger under shear and it is not correct to think of NIMs as a suspension of nanoparticles in a solvent or polymer matrix but instead as composed of single units of nanoparticles which carry around their own "solvent". The experimental data in Figure 4 was fit with a modified form of the Krieger-Dougherty (K-D) equation to quantify the effective volume fraction of the cores and to gain some insight as to the degree of volume fraction increase which arises from the attached corona and associated canopy counter-ions. The modified K-D equation for this case has the form ${ }^{[64-66]}$ :

$$
\begin{gathered}
\eta_{\mathrm{o}} / \mu=\left(1-\mathrm{C} \varphi / \varphi_{\mathrm{m}}\right)^{-[\eta] \varphi m} \\
\mathrm{C}=(1+\delta / \mathrm{R})^{3}
\end{gathered}
$$

where $\eta_{\circ}$ is the zero-shear viscosity, $\mu$ is the viscosity of the pure amine, the effective volume fraction is defined as $\varphi_{\text {eff }}=C \varphi, \varphi_{m}$ is the maximum packing fraction, $R$ is the radius of the core 
particles, and $\delta$ is the thickness of the extra layer of material surrounding the core which represents the corona and canopy ( $\delta=$ corona thickness + canopy thickness).

The line in Figure 4 is the result of fitting equation (1) to data of the reduced viscosity with the $[\eta]=2.5$ which is the intrinsic viscosity for spheres. The K-D model fits the data for tertiary amine-based NIMs (line) almost exactly, following the trend in the data points to the divergence of the reduced viscosity. This fit yields $\varphi_{m}=0.632$ and $C=2.344$ which gives layer thickness of $\delta_{3^{\circ}}=2.955 \mathrm{~nm}$. A rough estimate for the diameter of the $3^{\circ}$ amine canopy, calculated from the radius of gyration of a fully extended molecule for a freely jointed chain, is $1.4 \mathrm{~nm}$. From this value and assuming the corona thickness on the particles is about $0.5 \mathrm{~nm}$, a value which is based on the actual size of the corona molecule, a theoretical $\delta_{3^{\circ} \text {,theo }} \sim 2 \mathrm{~nm}$ is obtained, which is again smaller than the observed experimental value. These fits show that the layer of adsorbed canopy surrounding the nanoparticle core is larger than expected from estimates of size of the corona and canopy molecules. This difference may be explained by considering the steric hindrance associated with packing the amine molecules on the surface of the nanoparticle core. It may be possible that the associated canopy counter-ions reside in layers surrounding each nanoparticle core, which then leads to an effectively larger unit consisting of the core, corona, and canopy. These extra layers increase the value of the effective volume fraction of the core nanoparticle and in turn lead dramatic increases in the zero-shear viscosity. Similar effects have been observed before where the presence of an extended corona on the surface of a particle increases the zero-shear viscosity of a suspension and has been attributed to an increase in the repulsive interactions between the particles ${ }^{[64]}$. There are then complex interactions among the constituents of NIMs which depends on their architecture and composition. Recent rheology measurements show that the tertiary amine in the salt form yields 
a viscosity which is four times larger than that of the neat amine. It is possible that part of the NIMs behavior is due to the formation of the ammonium salt. A detailed study of the ammonium salt vis a vis rheology of NIMs will be communicated in a future publication.

It is also useful to compare the rheological behavior of NIMs to hard spheres and solutions of polymeric brushes ${ }^{[67]}$, star polymers ${ }^{[68]}$ and core cross-linked star polymers ${ }^{[69]}$. Such suspensions can display a wide range of behavior, from hard sphere-like to typical polymer solution behavior and even features denoted as "molecular softness". Systems which display “molecular softness" show a reduced viscosity which diverges at effective volume fractions larger than the observed value of $\varphi=0.64$ for hard spheres. Upon comparison, the observations of trends in reduced viscosity for NIMs do appear similar to what is expected for hard spheres such as the fact that the effective maximum volume fraction returned from fits of equation (1) are so close to the value of 0.64 expected for hard spheres. But there are differences as well such as the large values obtained for the reduced viscosity when compared to hard sphere colloidal suspensions $^{[48,54]}$. The complex interplay between the corona and canopy, as well as between canopy molecules themselves also may lead one to believe that NIMs share properties of solutions of star, brush, and cross-linked star polymers, but further investigation is required before any statements can be made. We do not observe "molecular softness" in NIMs since the effective maximum packing fraction obtained from equation (1) yields values less than 0.64 whereas polymer solutions with this feature have been shown to have $\varphi_{m}>1^{[67,69]}$. From these comparisons it appears that the rheological properties of NIMs falls somewhere in between the extremes of a colloidal suspension and polymer solutions. The dynamics of the canopy and corona are still currently under investigation in order to fully determine how these interactions affect the flow of the cores during deformation. 
Small angle $\mathrm{x}$-ray scattering measurements were used to probe the internal microstructure of the cores and to study the effect it has on the rheology of NIMs. Since microstructure is determined by the interplay between components of NIMs, SAXS is an excellent method to get an idea of the types of interactions that exist in NIMs. Reports of colloidal suspensions indicate that the rheology of a suspension is ultimately determined by the microstructure ${ }^{[49,70-76]}$. Figure 5 shows results of small-angle $\mathrm{x}$-ray measurements of NIMs. We attempted to fit the SAXS intensity patterns with a polydisperse hard sphere interaction model ${ }^{[77]}$ to gain some insight as to the types of interactions that exist between the nanoparticle cores. The lines in Figure 5 are the resulting fits to the experimental data. Satisfactory fits were only obtained for data sets with very low concentrations of cores on the order of $\varphi \sim 0.01$. At these concentrations the samples exist in a state where there is a great deal of un-reacted canopy which may serve as an excess fluidization medium and the material appears to behave as a dispersion of hard spheres. The model starts to deviate from the experimental data at volume fractions above $\varphi=0.119$. Since the tertiary amine has a molecular weight of $850 \mathrm{~g} / \mathrm{mol}$, this molecule is expected to a hydrodynamic radius of $R_{3^{\circ}} \sim 0.7 \mathrm{~nm}$. The smaller canopy size in the systems based on the tertiary amine may allow for stronger interparticle interactions from unscreened charges on the corona of the nanoparticles since the spacing between particles is smaller and may explain the departure from hard sphere behavior at lower $\varphi$. We expect that for NIMs based on larger molecular weight amines, departure from hard sphere behavior will occur at higher $\varphi$ due to the increased interparticle spacing. The departure from hard sphere behavior as the core volume fraction is increased can be seen by the failure of the model to fit experimental data in the $q$ range below $0.4 \mathrm{~nm}^{-1}$. This behavior indicates the presence of other interparticle interactions that cannot be explained by standard hard sphere models. These extra interactions may be a result of 
charge repulsion which can arise from un-reacted acidic groups in systems with a subequivalence of amine which is consistent with the observed results in Figure 4 where the reduced viscosity increases to very high values. Another apparent feature in Figure 5 at the core concentration $\varphi=0.38$ is that the model predicts the appearance of a strong peak due to the structure factor of the particles. Even at such high volume fractions, these NIMs samples do not appear to show such peaks. The lack of observed structure from the SAXS measurements suggests that core microstructure is not the only explanation for the sharp increase in viscosity with volume fraction. Instead, it appears that the interplay between the nanoparticle-canopy, nanoparticle-nanoparticle and canopy-canopy interactions all seem to contribute to the observed rheology. Unpublished results show that the canopy is in fact quite mobile and can hop from one core to another, further complicating the degree of interactions in NIMs ${ }^{[78]}$. We note that the length scale accessible from SAXS measurements is only on the order of $60 \mathrm{~nm}$ or less, underscoring the need for studies using other scattering techniques such as USAXS and USANS to probe the microstructure of NIMs on longer length scales. We are currently planning future studies with USANS to study the microstructure formed by the entire assembly which includes the core, corona, and associated canopy molecules to further explain the observations in the rheology data.

\section{Thermal Properties and Local Dynamics of the Canopy}

In this section, we present the effects of core volume fraction on the thermal properties and local dynamics of the canopy. The thermal properties of NIMs were measured using Differential Scanning Calorimetry (DSC) which gives detailed information about the phase transitions that occur in the ethylene oxide (EO) units of the canopy. In addition, the local 
dynamics of the canopy were studied by impedance spectroscopy. Combining all of these measurements provides detailed insight into how the presence of the cores alters the properties of the canopy. In Figure 6, the DSC trace of the pure tertiary amine shows a large endotherm at $4.2^{\circ} \mathrm{C}$ corresponding to melting of the crystalline EO units with a heat of fusion of $76.4 \mathrm{~J} / \mathrm{g}$. Increasing the core volume fraction leads to a suppression of the endotherm and results in a decrease of the observed crystallinity of the EO units of the amine. In these systems the percentage of crystallinity decreases from $100 \%$ for the pure tertiary amine down to about $20 \%$ at a core volume fraction of $\varphi=0.20$. The decrease in crystallinity of EO is likely due to the increased confinement imposed by the presence of the cores. Similar effects have been reported for poly(ethylene oxide) (PEO) confined in layered silicates ${ }^{[79]}$. We suspect that the decrease in the crystallinity of the canopy is related to the sharp rise in viscosity of NIMs with increasing core volume fraction. Since the presence of the cores appears to impede the crystallization of the EO units of the canopy, they in turn may also hinder the motion of the nanoparticles during deformation which results in larger observed viscosities. Increasing $\varphi$ leads to a decrease of the interparticle spacing and forces the canopy to reside in a more compact layer around the cores, impeding the melting and crystallization of the EO units.

DSC and DS measurements were employed to further characterize the local dynamics of the canopy. Information about the molecular motions at short length scales related to the glass transition and sub-glass transition dynamics can provide detailed insight into the role of the cores and canopy. Figure 7 displays the DSC traces from the second heating cycle for tertiary aminebased NIMs at various core volume fractions with the data normalized by the weight percentage of canopy present in each sample. In the case of the pure canopy, a glass transition temperature, 
$T_{g}$, characterized by a step function in the specific heat, $C_{p}$, is not observed due to the high degree of crystallinity of EO present in the canopy. Even at very high resolution, Figure 7 shows only a very weak step-function around $-66^{\circ} \mathrm{C}$, corresponding to a specific heat strength $\left(\Delta C_{p}\right)$ of $0.25 \mathrm{~J} / \mathrm{g}-\mathrm{K}$, which is in the lower end of observed $\Delta C_{p}$ for polyethylene oxide which has a value of $\Delta C_{p}=0.88 \mathrm{~J} / \mathrm{g}-\mathrm{K}$ and a $T_{g}=-67^{\circ} \mathrm{C}^{[80]}$. By contrast, in the case of NIMs, a well defined step function is observed between $-44^{\circ} \mathrm{C}$ and $-48^{\circ} \mathrm{C}$ with a $\Delta \mathrm{C}_{\mathrm{p}}$ of $\sim 0.95 \mathrm{~J} / \mathrm{g}-\mathrm{K}$. Despite the difference in volume fraction, the $T_{g}$ and $\Delta C_{p}$ are very similar for all tertiary amine-based NIMs samples, indicating that molecular motions near the glass transition point of the canopy are unaffected by the presence of the cores. Thus, neither the size of the cores nor their volume fractions appear to have a considerable effect on the associated molecular motions at short length scales determined by the $T_{g}$.

Dielectric spectroscopy (DS) was used to further characterize the molecular motions associated with $T_{g}$ and sub- $T_{g}$ dynamics in the canopy of NIMs systems. The complex dielectric function $(\varepsilon)$ of glass-forming polymers is influenced by a variety of dipole relaxation processes, including (i) an Arrhenius temperature activated process ( $\beta$-relaxation) below the glass transition temperature, which corresponds to localized reorientations of dipole vectors; (ii) an $\alpha$-relaxation process that is related to liquid-to-glass transition dynamics and corresponds to the segmental motion of chains; and (iii) a normal-mode relaxation due to end-to-end vector (i.e., chain) dynamics. In addition to dipole relaxations, ionic motion due to concentration gradients or an applied electrical field may also contribute to the dielectric strength of polymers.

Figure 8 is an example of the dielectric loss spectra $(\varepsilon ")$ as a function of frequency $(f=$ $\omega / 2 \pi)$ for the tertiary amine used in this study at selected temperatures with similar dielectric loss 
spectra observed for all measured tertiary amine-based NIMs samples. At temperatures above the calorimetric $T_{g}, \varepsilon^{\prime \prime}$ reveals a single $\alpha$-relaxation process and an ionic conductivity term that dominates at low frequencies. Below $T_{g}$ only a single $\beta$-relaxation is observed. At each temperature the dielectric spectra was fit with the Havriliak and Negami $(\mathrm{H}-\mathrm{N})$ equation ${ }^{[26,81]}$ :

$$
\left[\varepsilon^{*}(\mathrm{~T}, \omega)-\varepsilon_{\infty}(\mathrm{T})\right] / \Delta \varepsilon(\mathrm{T})=1 /\left[1+\left(i \omega \tau_{\mathrm{HN}}(\mathrm{T})\right)^{\alpha}\right]^{\beta}
$$

where $\tau_{H N}(T)$ is the characteristic relaxation time, $\Delta \varepsilon(T)=\varepsilon_{0}(T)-\varepsilon_{\infty}(T)$ is the relaxation strength, $\alpha$ and $\beta$ are respectively, the symmetrical and asymmetrical broadening of the distribution of the relaxation times of the probed dynamic process, $\varepsilon_{0}$ and $\varepsilon_{\infty}$ are the limiting values for $\varepsilon^{\prime}$ at low and high frequencies, respectively, and $\varepsilon^{*}(T, \omega)=\varepsilon^{\prime}-\varepsilon^{\prime}$, where $\varepsilon^{\prime}$ is the real dielectric permittivity. The fitting procedure at each temperature is based on the dielectric loss spectra $\left(\varepsilon^{\prime \prime}(\omega)\right)$. The linear rise of $\varepsilon^{\prime \prime}(\omega)$ at low frequencies is caused by conductivity with a contribution in the form of $\varepsilon^{\prime \prime} \sim\left(\sigma_{0} / \varepsilon_{f} \omega\right)$, where $\sigma_{0}$ is the dc conductivity and $\varepsilon_{f}$ is the permittivity of free space. This conductivity term is therefore added to the fit of equation (3). An example of the fit to the experimental data using equation (3) plus the conductivity contribution is shown in Figure 8, where the dashed line represents the conductivity contribution and the dotted curve the H-N function.

The relaxation time at maximum loss, $\tau_{\max }$, can be extracted from $\tau_{H N}$ by using $^{[82]}$

$$
\tau_{\max }=\tau_{\mathrm{HN}}[\sin (\pi \alpha / 2(1+\beta)) / \sin (\pi \alpha \beta / 2(1+\beta))]^{-1 / \alpha}
$$

Figure 9 shows an Arrhenius plot of the relaxation time at maximum loss, $\tau_{\max }$, for the pure tertiary amine and for tertiary amine-based NIMs at various core volume fractions. We observe a 
single $\alpha$-process associated with the liquid-to-glass transition for the pure canopy and NIMs with a strong temperature dependence. The $\alpha$-process is faster for the pure canopy than for the NIMs, suggesting the molecular motions associated with the $T_{g}$ of the EO groups in the canopy are hindered by the presence of the cores. We hypothesize that screening of charges on the surface of the cores causes charged groups on the canopy to reside in a compact double layer around the core, thereby restricting the segmental motions related to $T_{g}$ of ethylene oxide units. Restriction of the EO chains near the surface of the core slows the molecular motions associated with the $T_{g}$, thus increasing their characteristic relaxation time. Similar restrictive behaviors have been reported in the literature, such as in the case of poly(ethylene) glycol (PEG) oligomer used in highly confined systems of EO chains attached to a para(phenylene) (PPP) rigid matrix ${ }^{[83]}$, poly(ethylene) oxide (PEO) chains grafted between silica nanoparticles ${ }^{[84]}$, and hybrid PEG inorganic gels ${ }^{[85]}$. The observed sub-glass dynamics ( $\beta$-relaxation) in NIMs and the pure canopy are very similar, showing Arrhenius activation energies in the narrow range of $35-38 \mathrm{~kJ} / \mathrm{mol}$ indicating that the localized reorientations of the dipoles on the canopy are unaffected by the cores. These results show that the presence of the cores does in fact have an effect on the canopy. The complex interactions between the cores and canopy result in several features shown not only in this section, but also in the presented rheological and structural results of the previous section.

\section{Conclusions and Future Work}

In this article, we discuss a new class of nanohybrid materials consisting of a nanoparticle core, a charged corona attached to the core, and an oppositely charged canopy. The hybrid nature of these materials provides a new platform with wide ranging properties and 
functionalities, accessible simply by tailoring the individual components of the material. We presented results for a model NIMs system based on $18 \mathrm{~nm}$ diameter silica nanoparticles as the core, a sulfonic acid terminated corona, and tertiary amines as the canopy. The presence of the cores is shown to influence the thermal, structural, and dynamical properties of the canopy systems themselves. The viscosity of the fluid can be controlled by varying not only the volume fraction of the core but the canopy geometry and molecular weight as well. It has also been shown that the dynamics of the core and canopy are complex and warrant further investigation.

NIMs based on other cores beside silica, including iron oxide, titania, zirconia, gold, as well as organic cores were also briefly reviewed, showing that NIMs is a powerful new platform that can be extended to materials of various sizes, shapes, and compositions, in order to synthesize hybrid materials of almost any functionality. Further studies are required to fully understand the structure-property relationships in NIMs since the wide array of constituents that can be used to synthesize these materials can lead an exceptional array of physical properties with promising applications. 


\section{References}

[1] N. A. Kotov, F. Stellacci, Adv. Mater. 2008, 20, 4221.

[2] E. P. Giannelis, Adv. Mater. 1996, 8, 29.

[3] E. P. Giannelis, Appl. Organomet. Chem. 1998, 12, 675.

[4] S. N. Bhattacharya, M. R. Kamal, R. K. Gupta, Polymeric nanocomposites: theory and practice, Carl Hanser Verlag, Munich 2008.

[5] R. Gangopadhyay, A. De, Chem. Mat. 2000, 12, 608.

[6] F. Hussain, M. Hojjati, M. Okamoto, R. E. Gorga, J. Compos Mater. 2006, 40, 1511.

[7] J. Jordan, K. I. Jacob, R. Tannenbaum, M. A. Sharaf, I. Jasiuk, Mater. Sci. Eng. A-Struct. Mater. Prop. Microstruct. Process. 2005, 393, 1.

[8] T. Kairn, P. J. Daivis, I. Ivanov, S. N. Bhattacharya, J. Chem. Phys. 2005, 123, 7.

[9] R. Krishnamoorti, R. A. Vaia, E. P. Giannelis, Chem. Mat. 1996, 8, 1728.

[10] E. Manias, A. Touny, L. Wu, K. Strawhecker, B. Lu, T. C. Chung, Chem. Mat. 2001, 13, 3516.

[11] S. S. Ray, M. Okamoto, Prog. Polym. Sci. 2003, 28, 1539.

[12] K. Park, R. A. Vaia, Adv. Mater. 2008, 20, 3882.

[13] R. Krishnamoorti, R. A. Vaia, J. Polym. Sci. Pt. B-Polym. Phys. 2007, 45, 3252.

[14] G. Garnweitner, M. Niederberger, J. Mater. Chem. 2008, 18, 1171.

[15] A. B. Bourlinos, R. Herrera, N. Chalkias, D. D. Jiang, Q. Zhang, L. A. Archer, E. P. Giannelis, Adv. Mater. 2005, 17, 234.

[16] R. Rodriguez, R. Herrera, L. A. Archer, E. P. Giannelis, Adv. Mater. 2008, 20, 4353.

[17] A. B. Bourlinos, S. R. Chowdhury, R. Herrera, D. D. Jiang, Q. Zhang, L. A. Archer, E. P. Giannelis, Adv Funct Mater 2005, 15, 1285.

[18] A. B. Bourlinos, V. Georgakilas, V. Tzitzios, N. Boukos, R. Herrera, E. R. Giannelis, Small 2006, 2, 1188. 
[19] J. Dupont, R. F. de Souza, P. A. Z. Suarez, Chem. Rev. 2002, 102, 3667.

[20] K. N. Marsh, J. A. Boxall, R. Lichtenthaler, Fluid Phase Equilibria 2004, 219, 93.

[21] T. Welton, Chem. Rev. 1999, 99, 2071.

[22] W. Xu, C. A. Angell, Science 2003, 302, 422.

[23] W. Xu, E. I. Cooper, C. A. Angell, The Journal of Physical Chemistry B 2003, 107, 6170.

[24] M. S. Kelkar, E. J. Maginn, J. Phys. Chem. B 2007, 111, 9424.

[25] T. Koddermann, D. Paschek, R. Ludwig, ChemPhysChem 2008, 9, 549.

[26] A. B. Bourlinos, E. P. Giannelis, Q. Zhang, L. A. Archer, G. Floudas, G. Fytas, Eur Phys $J E$ 2006, 20, 109.

[27] A. B. Bourlinos, A. Stassinopoulos, D. Anglos, R. Herrera, S. H. Anastasiadis, D. Petridis, E. P. Giannelis, Small 2006, 2, 513.

[28] A. B. Bourlinos, K. Raman, R. Herrera, Q. Zhang, L. A. Archer, E. P. Giannelis, Journal of the American Chemical Society 2004, 126, 15358.

[29] D. E. Katsoulis, Chem. Rev. 1998, 98, 359.

[30] Q. F. Li, R. H. He, J. O. Jensen, N. J. Bjerrum, Chem Mater 2003, 15, 4896.

[31] S. M. Haile, D. A. Boysen, C. R. I. Chisholm, R. B. Merle, Nature 2001, 410, 910.

[32] Y. S. Kim, F. Wang, M. Hickner, T. A. Zawodzinski, J. E. McGrath, J. Membr. Sci. 2003, 212, 263.

[33] O. Nakamura, I. Ogino, T. Kodama, Solid State Ion. 1981, 3-4, 347.

[34] A. J. Appleby, "FUEL-CELL ELECTROLYTES - EVOLUTION, PROPERTIES AND FUTURE-PROSPECTS", 1994.

[35] M. Susan, A. Noda, S. Mitsushima, M. Watanabe, Chem. Commun. 2003, 938.

[36] W. Xu, E. I. Cooper, C. A. Angell, J. Phys. Chem. B 2003, 107, 6170.

[37] A. B. Bourlinos, S. R. Chowdhury, D. D. Jiang, Y. U. An, Q. Zhang, L. A. Archer, E. R. Giannelis, Small 2005, 1, 80. 
[38] R. R. Bhattacharjee, R. Li, L. Estevez, D.-M. Smilgies, A. Amassian, E. P. Giannelis, J. Mater. Chem. 2009.

[39] A. W. Perriman, H. Colfen, R. W. Hughes, C. L. Barrie, S. Mann, Angew. Chem.-Int. Edit. 2009, 48, 6242.

[40] P. Hedvig, Dielectric spectroscopy of polymers, Hilger, Bristol, U.K. 1977.

[41] J. P. Runt, J. J. Fitzgerald, Dielectric spectroscopy of polymeric materials: fundamentals and applications, American Chemical Society, Washington, DD 1997.

[42] A. Schonhals, Application Note Dielectrics 1, Novacontrol, Berlin, Germany.

[43] F. E. Kruis, H. Fissan, A. Peled, J. Aerosol. Sci. 1998, 29, 511.

[44] C. J. Murphy, T. K. San, A. M. Gole, C. J. Orendorff, J. X. Gao, L. Gou, S. E. Hunyadi, T. Li, J. Phys. Chem. B 2005, 109, 13857.

[45] A. H. Lu, E. L. Salabas, F. Schuth, Angew. Chem.-Int. Edit. 2007, 46, 1222.

[46] S. O'Brien, L. Brus, C. B. Murray, J. Am. Chem. Soc. 2001, 123, 12085.

[47] T. Trindade, P. O'Brien, N. L. Pickett, Chem. Mat. 2001, 13, 3843.

[48] J. F. Brady, Journal of Chemical Physics 1993, 99, 567.

[49] M. Chen, W. B. Russel, J. Colloid Interface Sci. 1991, 141, 564.

[50] M. E. Fagan, C. F. Zukoski, J. Rheol. 1997, 41, 373.

[51] R. A. Lionberger, W. B. Russel, J. Rheol. 1994, 38, 1885.

[52] J. Mellema, C. G. Dekruif, C. Blom, A. Vrij, Rheologica Acta 1987, 26, 40.

[53] P. N. Pusey, P. N. Segre, O. P. Behrend, S. P. Meeker, W. C. K. Poon, Physica A 1997, 235,1 .

[54] J. C. Vanderwerff, C. G. Dekruif, J. Rheol. 1989, 33, 421.

[55] H. Watanabe, M. L. Yao, A. Yamagishi, K. Osaki, T. Shitata, H. Niwa, Y. Morishima, Rheologica Acta 1996, 35, 433.

[56] Y. H. Hyun, S. T. Lim, H. J. Choi, M. S. Jhon, Macromolecules 2001, 34, 8084.

[57] R. Krishnamoorti, E. P. Giannelis, Macromolecules 1997, 30, 4097. 
[58] V. Pryamitsyn, V. Ganesan, J. Rheol. 2006, 50, 655.

[59] Q. Zhang, L. A. Archer, Langmuir 2002, 18, 10435.

[60] J. J. Stickel, R. L. Powell, Annual Review of Fluid Mechanics 2005, 37, 129.

[61] A. J. Poslinski, M. E. Ryan, R. K. Gupta, S. G. Seshadri, F. J. Frechette, J. Rheol. 1988, $32,703$.

[62] A. J. Poslinski, M. E. Ryan, R. K. Gupta, S. G. Seshadri, F. J. Frechette, J. Rheol. 1988, 32,751 .

[63] W. B. Russel, Annual Review of Fluid Mechanics 1981, 13, 425.

[64] L. N. Krishnamurthy, E. C. Weigert, N. J. Wagner, D. C. Boris, J. Colloid Interface Sci. 2004, 280, 264.

[65] P. F. Luckham, M. A. Ukeje, J. Colloid Interface Sci. 1999, 220, 347.

[66] J. Mewis, J. Vermant, Progress in Organic Coatings 2000, 40, 111.

[67] D. Vlassopoulos, G. Fytas, S. Pispas, N. Hadjichristidis, Physica B 2001, 296, 184.

[68] J. Roovers, Macromolecules 1994, 27, 5359.

[69] T. K. Goh, K. D. Coventry, A. Blencowe, G. G. Qiao, Polymer 2008, 49, 5095.

[70] B. J. Ackerson, N. A. Clark, Physical Review A 1984, 30, 906.

[71] B. J. Ackerson, J. B. Hayter, N. A. Clark, L. Cotter, Journal of Chemical Physics 1986, $84,2344$.

[72] J. F. Brady, J. F. Morris, J. Fluid Mech. 1997, 348, 103.

[73] L. B. Chen, B. J. Ackerson, C. F. Zukoski, J. Rheol. 1994, 38, 193.

[74] M. D. Haw, W. C. K. Poon, P. N. Pusey, Phys. Rev. E 1998, 57, 6859.

[75] H. M. Laun, R. Bung, S. Hess, W. Loose, O. Hess, K. Hahn, E. Hadicke, R. Hingmann, F. Schmidt, P. Lindner, J. Rheol. 1992, 36, 743.

[76] A. Sierou, J. F. Brady, J. Rheol. 2002, 46, 1031.

[77] S. R. Kline, J. Appl. Crystallogr. 2006, 39, 895. 
[78] M. L. Jespersen, P. A. Mirau, E. vonMeerwall, R. Rodriguez, E. P. Giannelis, R. A. Vaia, ACS Nano 2009 (In Preparation).

[79] S. C. Warren, M. J. Banholzer, L. S. Slaughter, E. P. Giannelis, F. J. DiSalvo, U. B. Wiesner, Journal of the American Chemical Society 2006, 128, 12074.

[80] S. Swier, R. Pieters, B. Van Mele, Polymer 2002, 43, 3611.

[81] Havrilia.S, S. Negami, Polymer 1967, 8, 161.

[82] A. Schoenhals, F. Kremer, Broadband Dielectric Spectroscopy, Springer, Berlin 2002.

[83] M. Mierzwa, G. Floudas, M. Neidhofer, R. Graf, H. W. Spiess, W. H. Meyer, G. Wegner, J. Chem. Phys. 2002, 117, 6289.

[84] M. E. Brik, J. J. Titman, J. P. Bayle, P. Judeinstein, Journal of Polymer Science Part BPolymer Physics 1996, 34, 2533.

[85] P. Lesot, S. Chapuis, J. P. Bayle, J. Rault, E. Lafontaine, A. Campero, P. Judeinstein, Journal of Materials Chemistry 1998, 8, 147. 


\section{Graphical Abstract The Synthesis and Properties of Nanoscale Ionic Materials}

Robert Rodriguez, Rafael Herrera, Athanasios B. Bourlinos, Ruipeng Li, Aram Amassian, Lynden A. Archer, * Emmanuel P. Giannelis

Nanoscale ionic materials (NIMs) are hybrid materials consisting of a nanometer sized core, a charged corona covalently attached to the core, and an oppositely charged canopy. Because of the hybrid character of NIMs, their physical properties can be tailored by varying the size, shape and composition of the core, corona, and canopy as well as external parameters such as temperature, mechanical deformation, and electric and magnetic fields.

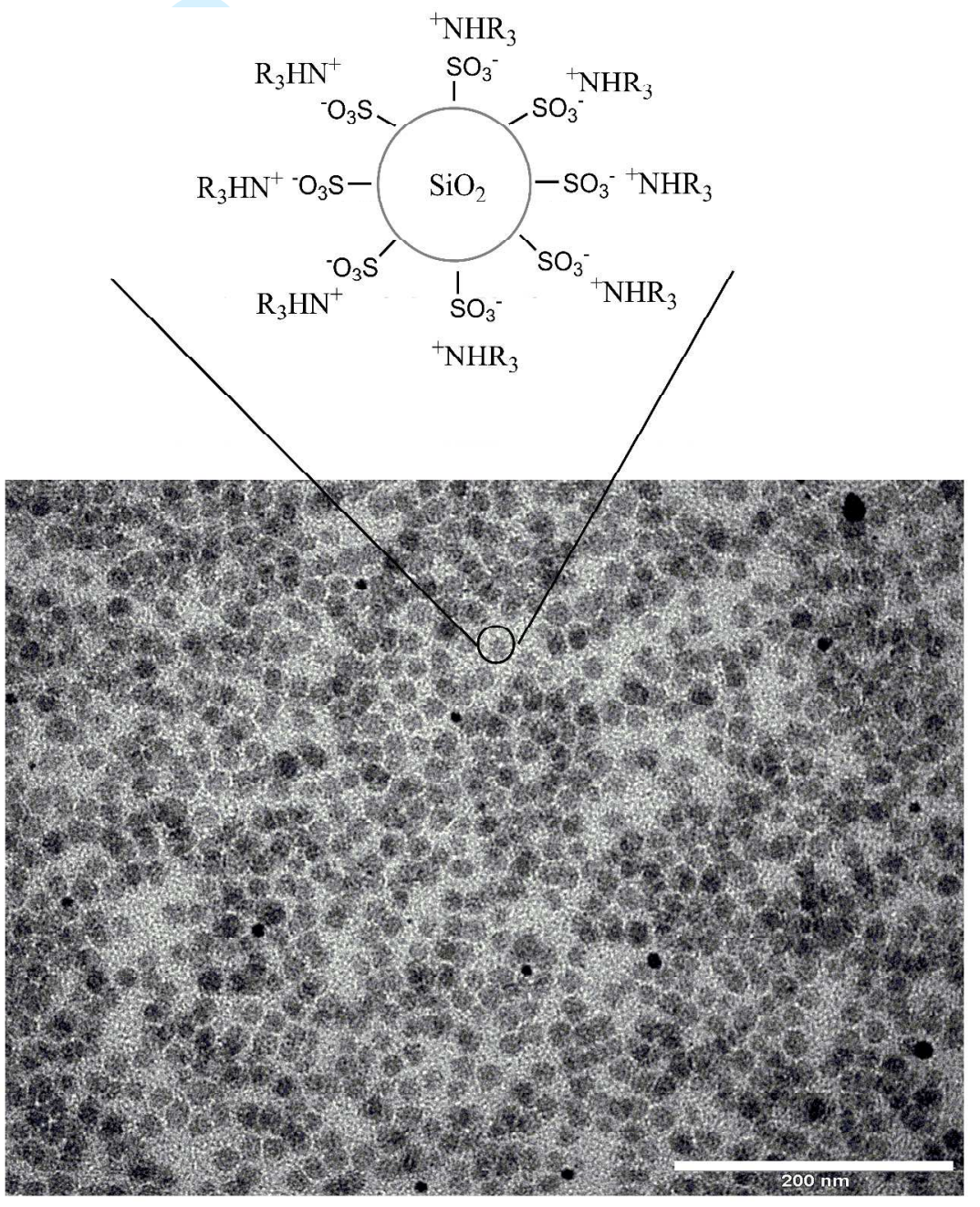


a)

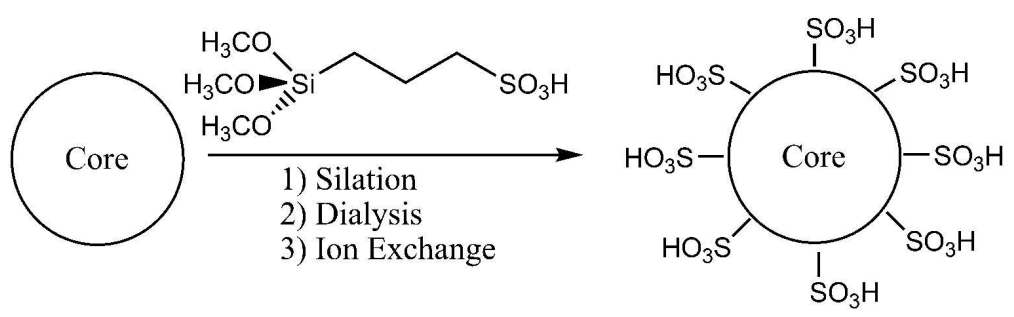

b)

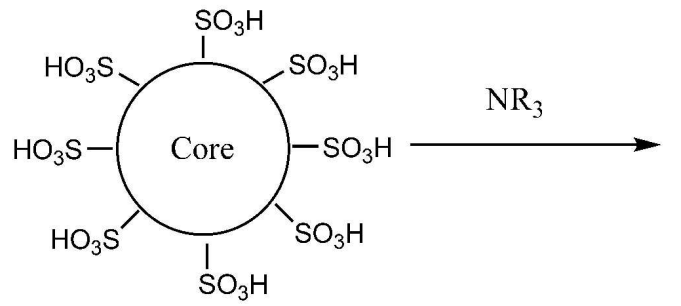

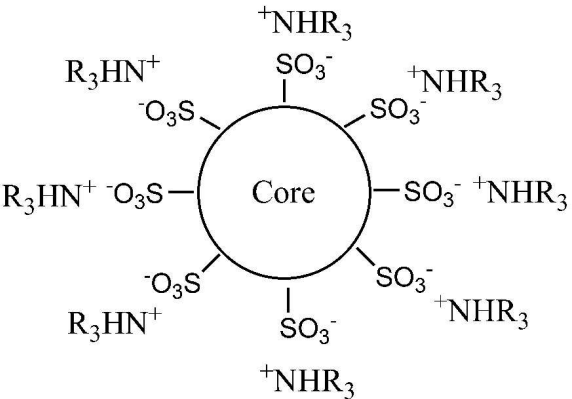

c)

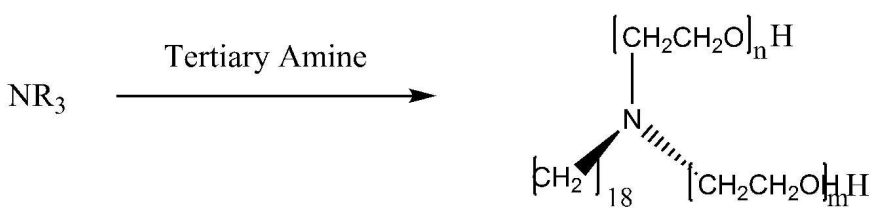

Scheme 1. Typical schematic for second generation NIMs synthesis. a) The nanoparticle cores are first surface functionalized by covalently attaching a sulfonic acid terminated silane. The nanoparticle suspension is then purified by dialysis for a minimum of three days, followed by an ionexchange to protonate the sulfonic acid groups. b) The acidic nanoparticles are then reacted with a weak base in the form of an amine. The acid-base neutralization leads to charged nanoparticle stabilized by an associated organic counter-ion in the form of the cationic amines. c) A tertiary amine (Akzo Nobel, Ethomeen ${ }^{\circ} \mathrm{C} / 25$ ) was selected for this study. $168 \times 144 \mathrm{~mm}(600 \times 600 \mathrm{DPI})$ 


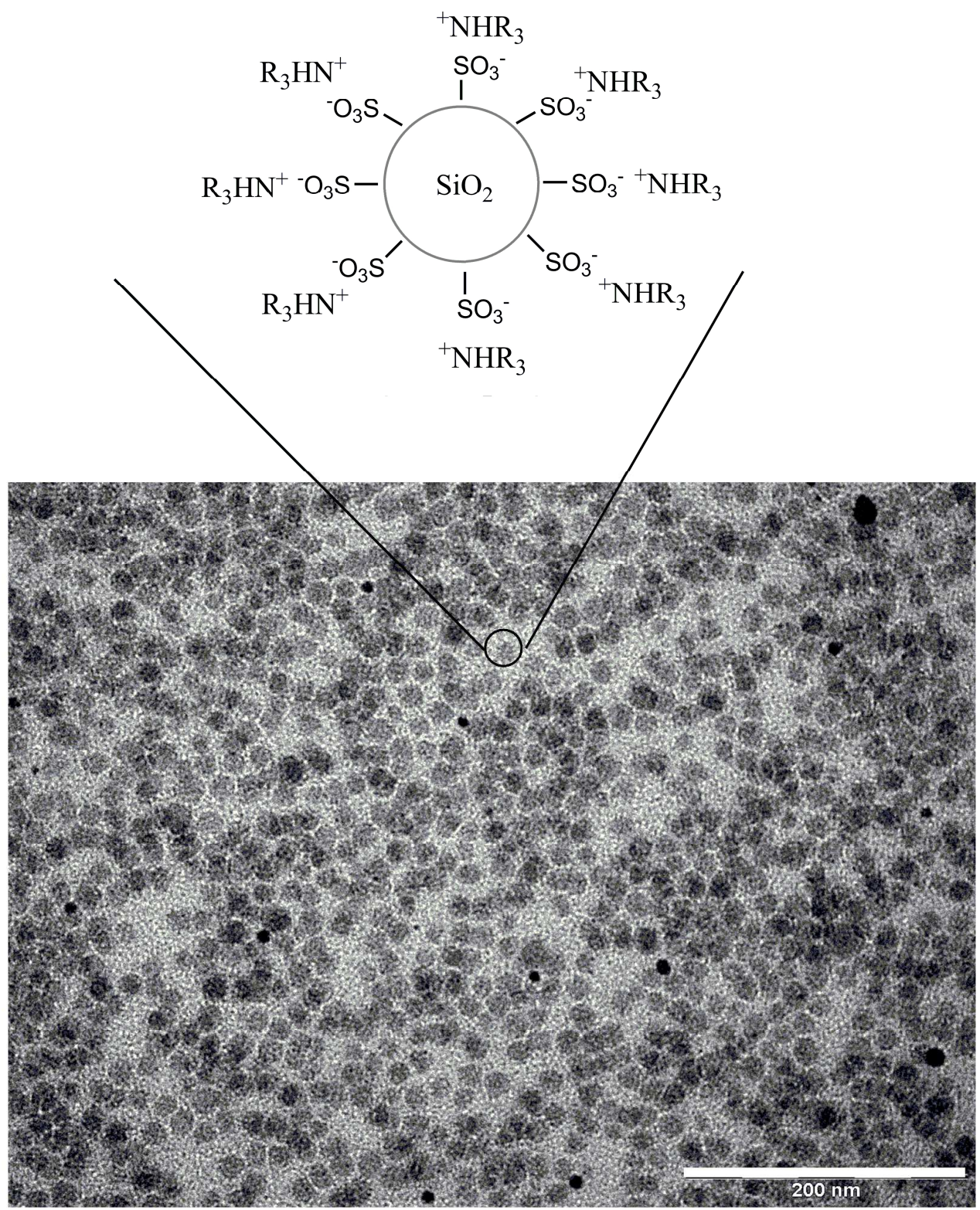

Figure 1. Schematic showing NIMs in final state, with attached corona and associated counter-ions. TEM image showing tertiary amine based-NIMs after solvent removal. TEM shows that nanoparticles are not aggregated and remain as single units carrying around their own corona and canopy. $137 \times 169 \mathrm{~mm}(600 \times 600 \mathrm{DPI})$ 
Figure 2. Titration curve for reaction of $18 \mathrm{~nm}$ diameter functionalized silica particles with the tertiary amine ( $\mathbf{a})$ used in this study. The equivalence point of the reaction is defined as the area of the curve that shows the largest change in slope. For NIMs based on the tertiary amine this occurs at a core volume fraction of $\varphi=0.308$ ( $\varphi$ Organic $=0.692$, where $\varphi$ Organic is defined as the volume of present corona and canopy). $279 \times 216 \mathrm{~mm}(600 \times 600 \mathrm{DPI})$ 


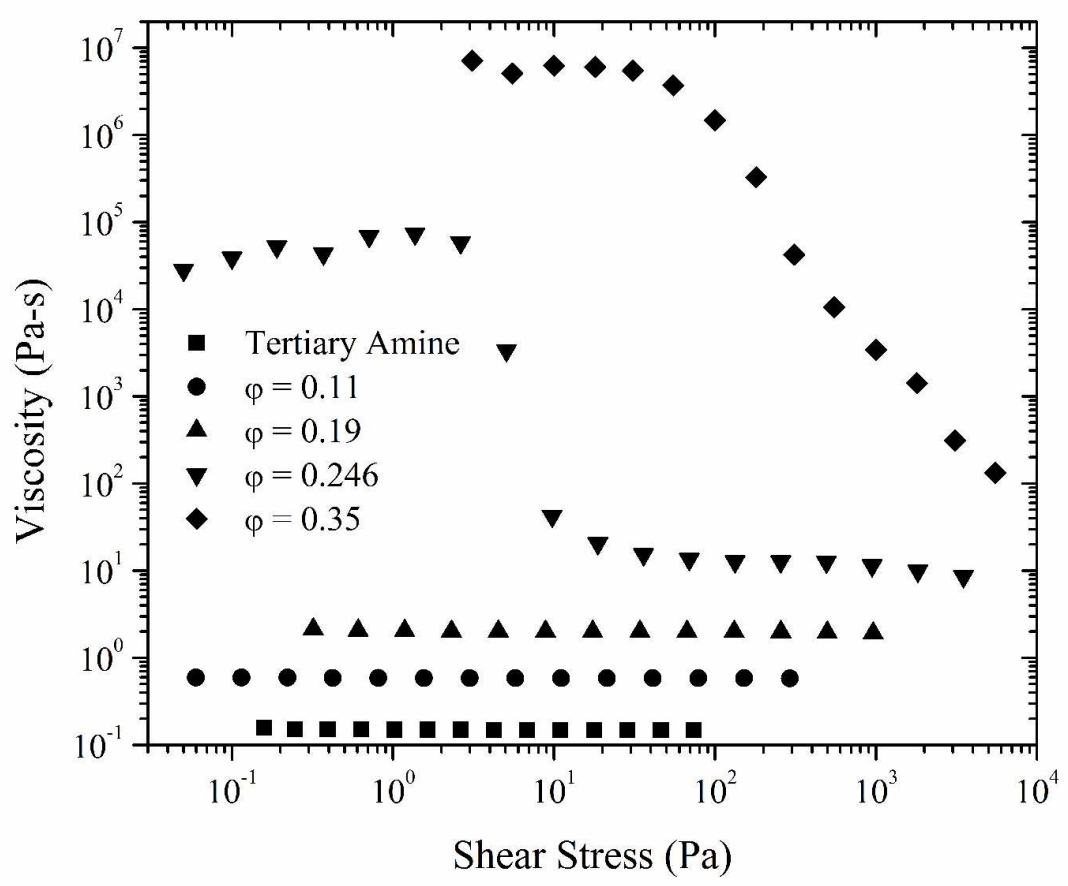

Figure 3. Flow curves for NIMs the tertiary amine. Flow curves display behavior ranging from Newtonian to non-Newtonian with shear thinning. $279 \times 216 \mathrm{~mm}(600 \times 600 \mathrm{DPI})$ 


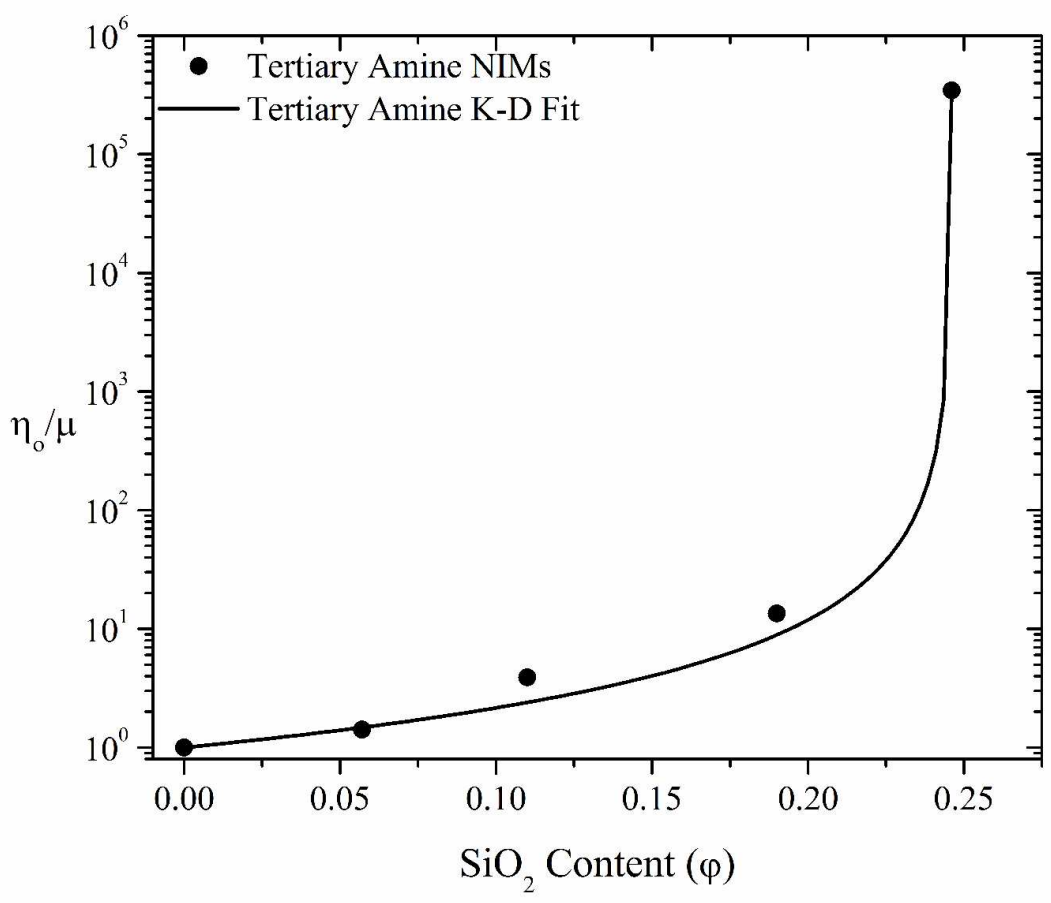

Figure 4. Plot of reduced viscosity (ratio of zero-shear viscosity of NIMs and viscosity of pure amine) as a function of core volume fraction for NIMs based on the tertiary amine $(\bullet)$. Line is a fit of the modified K-D equation. $279 \times 216 \mathrm{~mm}(600 \times 600 \mathrm{DPI})$ 
Figure 5. Small-angle $\mathrm{x}$-ray intensity patterns for NIMs based on the tertiary amine at various core volume fractions. Curves are shifted vertically for easier viewing. Lines are fits of a polydisperse hard sphere model. $279 \times 216 \mathrm{~mm}(600 \times 600 \mathrm{DPI})$ 
Figure 6. DSC curves for tertiary amine-based NIMs at various core volume fractions. Plots are expressed as heat flow of pure canopy with the mass of the core factored out. $279 \times 215 \mathrm{~mm}(600 \times 600 \mathrm{DPI})$ 
Figure 7. DSC traces of NIMs based on tertiary amine as the canopy. The plots are expressed as heat capacity of pure canopy with the mass of the cores factored out. $279 \times 215 \mathrm{~mm}(600 \times 600 \mathrm{DPI})$ 


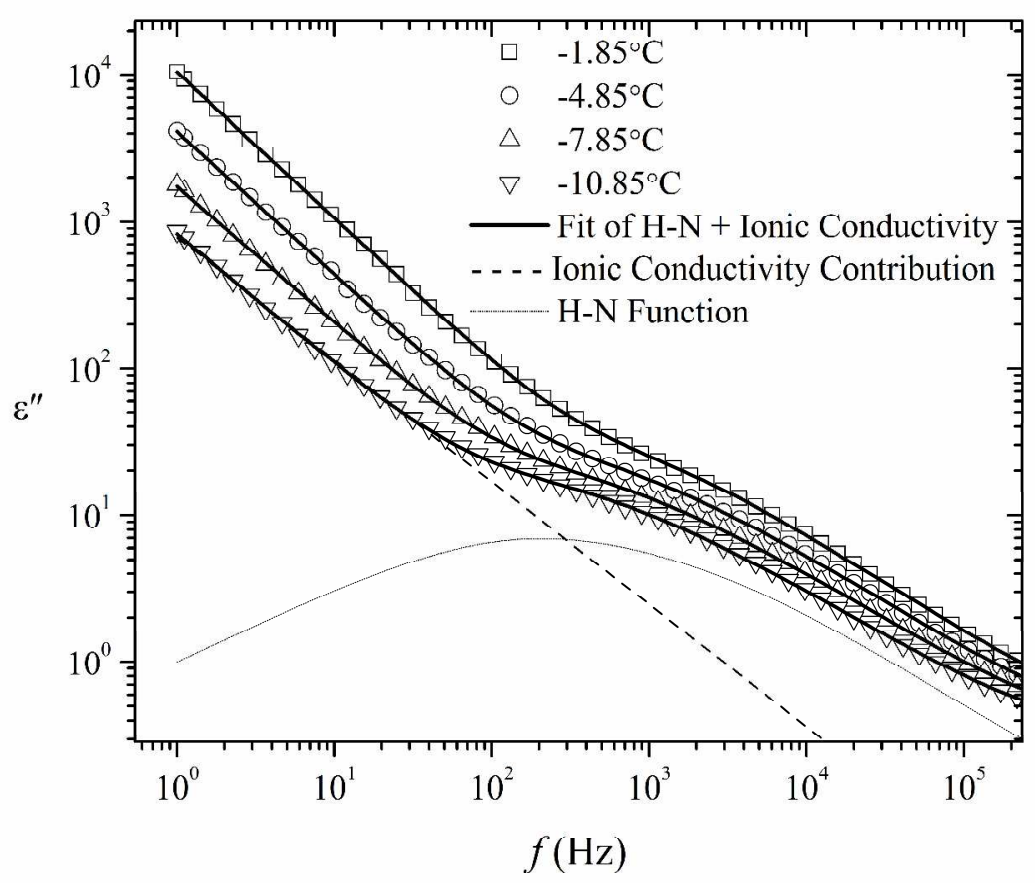

Figure 8. Dielectric-loss $\varepsilon^{\prime \prime}(\omega)$ spectra for tertiary amine shown at selected temperatures. The spectra show contributions from one relaxation process and ionic conductivity. The lines are results of example fits to the $\mathrm{T}=-10.85^{\circ} \mathrm{C}$ curve with the summation of the $\mathrm{H}-\mathrm{N}$ function (dotted curve) and a conductivity contribution (dashed line). $279 \times 215 \mathrm{~mm}(600 \times 600 \mathrm{DPI})$ 
Figure 9. Relaxation map for tertiary amine-based NIMs showing two types of relaxation mechanisms, $a$ and $\beta$-type relaxations. All NIMs samples, including pure tertiary amine canopy have Arrhenius activation energies in the range $35-38 \mathrm{~kJ} / \mathrm{mol}$. $279 \times 215 \mathrm{~mm}(600 \times 600 \mathrm{DPI})$ 


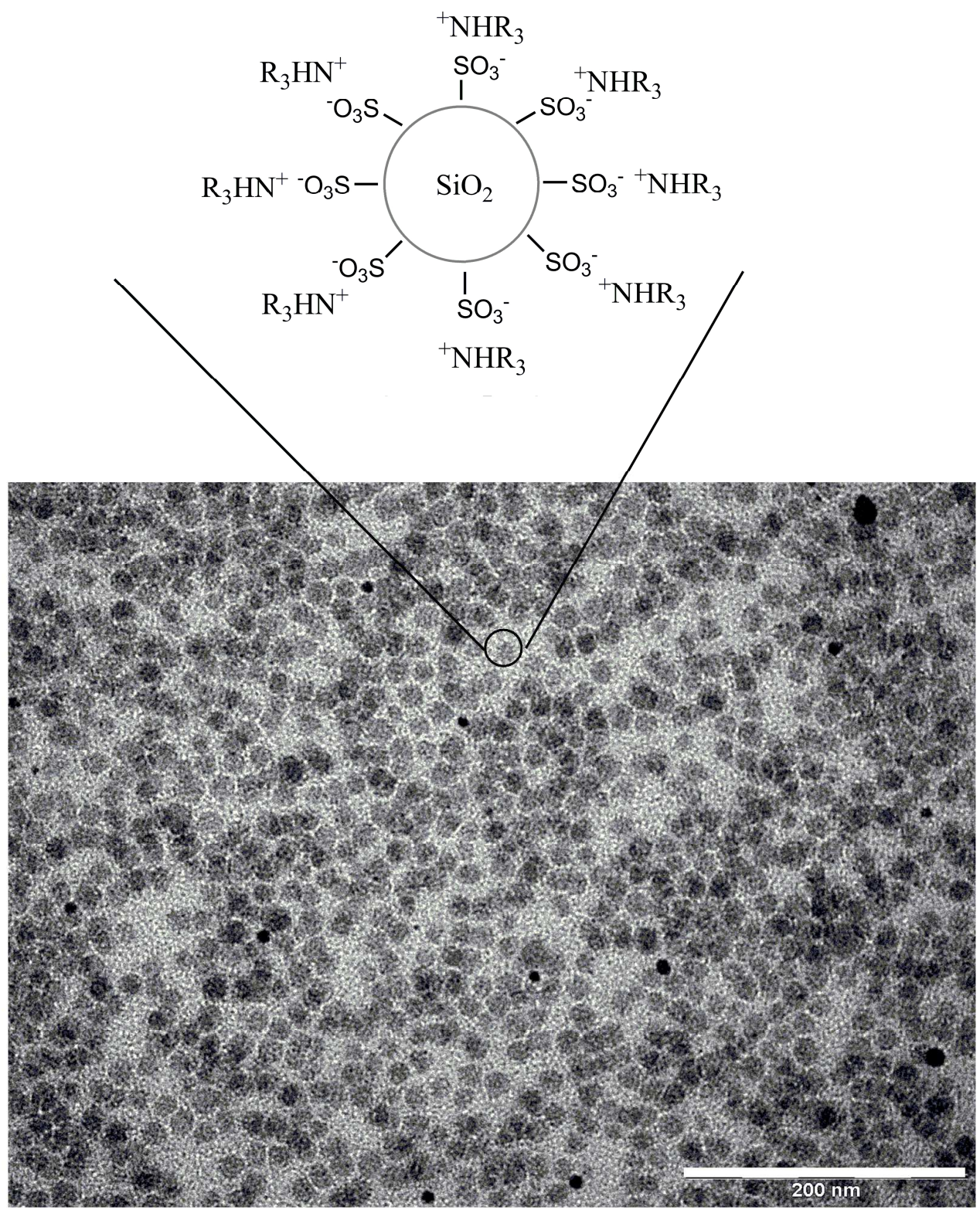

Nanoscale ionic materials (NIMs) are hybrid materials consisting of a nanometer sized core, a charged corona covalently attached to the core, and an oppositely charged canopy. Because of the hybrid character of NIMs, their physical properties can be tailored by varying the size, shape and composition of the core, corona, and canopy as well as external parameters such as temperature, mechanical deformation, and electric and magnetic fields. $137 \times 169 \mathrm{~mm}(600 \times 600 \mathrm{DPI})$ 